\title{
With The Implementation Of Ontologies To The Intelligence And More Efficient Serving of The Users In The Public Administration
}

\author{
Mladen Radivojevic ${ }^{1}$, Kristijan Ristic ${ }^{2}$, Sladjana Lolic ${ }^{3}$ \\ ${ }^{1}$ University of Business Studies, 78000 Banja Luka, Bosnia and Herzegovina \\ radivojevicmladen60@gmail.com \\ ${ }^{2}$ University of Business Studies, 78000 Banja Luka, Bosnia and Herzegovina \\ ristic.kristijan@yahoo.com \\ ${ }^{3}$ University of Business Studies, 78000 Banja Luka, Bosnia and Herzegovina \\ Iolicm@blic.net
}

\begin{abstract}
We are facing the challenge of increasing application of new technological solutions in the public administration among which are the concept of ontology and the increasing exchange of knowledge and information with which we deal in this paper. This should be the primary drivers of power for the transition of work of the public administration to the new concept of e-m-i-Government. In this paper we perceive the IT situation in this region, development trend of ontology in the public administration and we suggest the solutions for public administration in Bosnia and Herzegovina to implement new solutions. In this paper we suggest the process organization of work and serving in the public administration as a basis for more efficient and more effective implementation of ontologies and the exchange of knowledge with the use of new technological solutions. Likewise, we propose the solution which is based on a single access point for all service users regardless of the communication channel.

The implementation of ontologies and intelligence in the public administration will observe as the basis for offering services, personalization and self-service.
\end{abstract}

Keywords: process organization, ontology, public administration, new service.

\section{Council for Innovative Research}

Peer Review Research Publishing System

Journal: International Journal of Management \& Information Technology

Vol. 9, No. 1

editor@cirworld.com

www.cirworld.com, member.cirworld.com 


\section{INTRODUCTION}

We live in the time of limited budgets, big demographic changes and growing global competition. Those are very important driving forces for the transition to work in the new environment. Some business systems of the developed countries are already in the advanced stages of implementation of the concept of ontology and intelligent business while other countries do not even consider it. Good practice of such concept as in some business systems and in some administrations, administrative organizations or local government units (public administration) suggest that there is no serious doubt and data on savings and benefits encourage others to move to the implementation of ontology as a foundation for electronic, mobile and intelligent administration e-m-i-Government. It now reduces the costs of collecting, processing and transfer of information and knowledge and it must lead to the change in current way of working and serving in the public administration. New technologies and new service solutions must be viewed in a much broader context than hitherto. Information and knowledge that serving creates and that affects them, people who participate in that process, procedures that define the service requirements and a set of interrelated technologies and methodologies which those information and knowledge process, transfer and keep, are changing the current way of work of public administration and its serving.

Technological solutions of the electronic and mobile administration (e-m-i-Government) based on the ontologies should provide transition to the intelligent business in the public administration (e-m-i-Government [1]). This will certainly improve the efficiency and effectivenes of its work. The greater implementation of new technological solutions provides more efficient communication between public administration as service provider and citizens and business systems as its users. The concept of e-m-i-Government enables service users a service without physical interaction with the service providers (administrations, administrative organizations and local government unitsmunicipalities/cities).

Our aim in this paper is to suggest improvements in the access to the public services (services provided by the public administration) through more efficient use of the knowledge and the application of ontologies. We want to improve access to public information through different access to the service systems. The service customer wants to have a choice, which communication channel to use for access and provision of services and in this way the service would be faster and cheaper.

The introduction of e-m-Service [2] and the concept of ontologies should be implemented to enable service users (legal and natural persons) to perform their obligations to the state faster and more efficient, without the counter and waiting in line. Some countries have already provided that so the service customers can search for available services, have electronic identification, fill out a form, submit a document, electronically sign the application and pay the fee.

\section{PUBLIC ADMINISTRATION}

With the Law of the Republic Administration [3] precisely are defined the tasks of the public administration: the policy development, monitoring, legislative activity, enforcement of laws and other regulations, administrative supervision, making decisions in the administrative proceedings on the rights and obligations of the participants in the proceeding, acting in the misdemeanor proceeding, custody of public offices and other professional administrative affairs.

The prevailing opinion is that the public administration of these areas is based on the traditional bureaucratic procedures favoured by routine and repetitive proccedures. Its activities are more related to the mitigation of problems than on solving them in a qualitative way, although it should be done in accordance with the expectations of the citizens (service users).

Administration, administrative organizations and local self-government units do not follow profit as the main objective of the work and therefore they have no need for maximum engagement. It would be good when the objective of the public administration in Bosnia and Herzegovina was cheap and quality service tailored by the wishes of the users.

The objectives set in front of the public administration are [4]: expertness and efficiency, increase of professionalism and knowledge, transparency in work, linking with the use of new technologies and providing cheaper services. In order to achieve all this it is necessary to: Implement the reform of the public administration. Provide better coordination in the process of serving. Increase the professionalism and stability. Increase organizational efficiency. Reduce the number of management levels. Ensure the decentralization of serving (to the level of local communities). Provide more effective rewarding system. Reduce the differences between the highest and the lowest income. Provide an objective measurement of knowledge and abilities. Conducting continuous improvement and learning. Ensure transparency of the work. Ensure the depoliticization of the public administration. Increase the use of information and communication technologies. Part of the specific services leave to the private sector. Reduce the cost of services. Identify the elements for the check of the quality of regulations. Ensure that the institutions can prepare better quality regulations. Using more knowledge in the work and serving, .....

Under the body conducting a procedure, ie deliberates in the administrative matters it is understood: the administrative body, other state bodies, administrative organization, as well as the enterprise, institution and other organizations that are legally entrusted the exercise of the public powers [5].

The modernization of the public administration (administrations, administrative organizations and local selfgovernment units), the professionalization of the work and providing faster and cheaper services are essential preconditions for the development of the society. Transparent, open, and reliable public administration is an assumption of better serving and satisfaction of the user with the service. 


\section{1. Public services}

A public service is a term which is most frequently used to mean the services provided by public administration to its citizens [6]. These services are essential to the functioning of the modern society and must be accessible to all citizens. Public services include: education, distribution of the electricity and gas, fire protection, health, police, purity, production and distribution of water and the like.

If the public administration collects knowledge, channels it and motivates its employees to share, use and create new knowledge and based on that new values and better services than there is a chance to be more efficient and effective.

Now the trend is intelligent serving and it consists of the following set of characteristics:

- Acquisition and the use of knowledge, skills, experiences and other intangible qualities as the basis for the development process to create better service.

- The development of the entrepreneurial culture with the basics in the teamwork.

- Directing team members (all employees) on the cooperation and exchange of knowledge and the development of correct service relations within the administration itself and its surroundings.

In the public administration it should be asked the following questions: How intelligent is our business? How well does our staff know and understand the forces that run serving and determine our future? How do we gain knowledge and exchange it? How to use this knowledge to better serving? How to reach this service intelligence that turns the traditional services upside down?

Public administration should deliver public services (its services) on a transparent, democratic, efficent and effective manner to satisfy the needs of the user for the service. This can be done directly or by using new technologies. With the delivery of public services is related a social consensus that certain services should be available to everyone, regardless of things such as nationality, race, gender, salary, status, political party affiliation and the like. According to the Contract concerning the establishment of the European Community in Amsterdam in 1999, public services ( here called "services of general interest») are marked as the administrative activities of general interest, established by the public administration for which they are responsible, even when their management is transferred to a public or private operator.

In the delivery of the service in which participate more administrations, administrative organizations or local selfgovernment units it must be established such an infrastructure and organization that can meet the needs of each user. The user does not need to go from one to the other body of the administration, from one to the other counter. The service must get in one place, and at the same time use any communication channel.

\section{2. Service processes}

If we want for the public administration in this region works more efficiently there should be established coherent processes between all administrations, administrative organizations and local self-government units (cities and municipalities). By optimizing the serving process it can be provided that a certain service in the service chain is available just when it is needed by any user. We can only imagine that a service is requested (submit a request) via any communication channel, transmited to a computer in the public administration and processed and the user is transmitted appropriate decision, certificate, resolution, confirmation, information,.... . How much is the pleasure of the user that is served? This kind of service in a great extent can provide a new concept of e-m-Service [7] based on ontologies.

A key role for efficient service has the shaping of the processes. Quality organization enables more economical service processes and increases the speed and the quality of service. Quality information and knowledge, connection between public administration and the service users and information connections between the parts of the public administration have a positive effect on more efficient serving. Efficiency in the public administration means that the taxes payed by citizens and business systems are more efficiently turning into high quality public services.

Althought it may seem too optimistic, but it should optimize the service processes in the public administration. All who believe that ideally designed service processes can not be achieved are not right. We can achieve coherence off all processes and of all segments of the public administration, all business systems and all service users. In order to achieve this we need much greater application of new technologies and a complete implementation of ontologies.

Why public administration doesn't accomplish that? If we don't mix everything with politics, our laziness and lack of cooperation we can do something positive by which we would be recognizable. Most of you know what now make us recognizable. Why we wouldn't be a country with the best and cheapest service. Why we would not be the country that has the most satisfied service users in the public administration? Why not share knowledge and good practice?

If we look for the answers on the previous questions from the service users and from the employees in the public administration they would surely be different. Surely those who make decisions should initiate, lead and direct the implementation. Are they interested in that? Do they want to do it? Who is he that can threaten the position of untouchable, privileged, alienated and very indifferent to change anything. The monopoly does not force him to do such thing. Citizens certainly look that in a different way. The problem of public administration is the lack of quality staff, the staff who knows and wants changes for better. The problem is also with the users that have high expectations and they don't do anything to make them true. 
For a public administration to improve its service processes must implement a great number of changes. Traditional organizational units (departments, services, sectors, classes, ...) must be replaced by process units, and in that way the work tasks become more flexible and extensive. When selecting the employees for the performance of certain tasks (provision of services), their education, knowledge, abilities and skills take precedence over affiliation of the organizational unit or even a political party. Managerial workers become "coaches and mentors" and the employees are directed not to execute commands of the managers but to meet the demands of service users (legal and natural persons). The fees of the employees are determined by the number of performed tasks, their quality, teamwork, innovation, collaboration, the opinion of the service users[8],...

Characteristics of such process organization are:

- The teams are formed according to the key processes, and not tasks or functions.

- The basis of organizational design and implementation are independent teams and not individuals.

- Responsibility for each process lies on its owner.

- All team members must possess the knowledge, skills, tools, motivation and authorization for making decisions which are related to more efficient work.

- Teams have complete freedom in thought and work.

- Efficiency is measured by the achievement of the objective and the satisfaction of the service user.

- The basis of serving are openness, trust, cooperation, sharing of knowledge, and all is focused on continuous improvement.

In the process organization the employees become members of teams whose main task is to contribute to better serving and to create values for customers.

The process organization would provide to the public administration: a bigger focus on the user of the service, better communication and more quality responce to the requirements (by defining the limits of the user and the supplier of the process ), process management (providing much more than the management of individual organizational parts), by determining the process owner and responsible for the process (avoiding the fragmentation of responsibility), very simple way of modification of organization of the serving, and better management of all resources.

In order to implement the process organization in the public administration it is necessary: to define the key service processes, implement organization serving about processes and not functions, eliminate all activities that do not increase the value or not contribute to key objectives, reduce the functions and the number of employees, name the team that will be the owner of every key process, use more new technologies, the employees provide required knowledge, authority and information necessary for efficient work, improve training, rewarding, salary and budget system.

Traditional hierarchical structure is almost impossible to measure and improve, while in process oriented organizations parametres that represent its basis (costs, time, quality, customer satisfaction and etc.) are constantly analyzed and adjusted.

The greatest value of the transition to the process oriented public administration is the transition to the point of view that the processes and not functions are those that create value for both the public administration and the users of its services.

A feature of this serving is the greater use of new technologies, significant commitment to the users of services which is why they are much happier. Teamwork, cooperation, exchange of knowledge with the use of ontology and the possibility of division of the resposibility has a positive effect on the quality of work and the motivation of the employees. These changes in serving are very hard to implement in the bureaucratized structures with strictly divided responsibilities, salaries received by the workplace and not by the results of the work. In these administrations, administrative organizations and local self-government units resistance to change is great, which makes it difficult to implement any kind of change or improvement.

One must bear in mind that every concept has its good and certainly bad sides. Here we haven't and we will not mention bad sides because they are of less significance in relation to the positive effects that can be achieved in particular in the use of electronic, mobile and intelligent business based on ontology and the exchange of knowledge.

\section{THE EXISTING REGISTRIES}

Experiences show that in the public administration key domain data are: proctor, population, business systems, finance, state legislation (Constitution, laws, (generic documents)) and statistics and statistical indicators.

A major problem in Bosnia and Herzegovina $(\mathrm{B} \& \mathrm{H})$ is that the data (registers) are recorded separately. We have the data that are recorded at the state level (Council of Ministers), the entity level (Republic of Srpska and Federation of $\mathrm{B} \& \mathrm{H}$ ) and the level of District of Brcko. All registers are strictly separated except those which leads IDDEEA [9] and which are common for the whole B\&H. Registers (data) which leads IDDEEA are [10]: Register of personal identification numbers (PIN); Register of permanent and temporary residence of citizens of Bosnia and Herzegovina; Register of identity cards of citizens of Bosnia and Hercegovina; Register of civic, official and diplomatic passports; Register of driving licenses; Register of motor vehicles registration and registration documents; Register of identity cards for foreign nationals and register of fines and infringements.

We will list only fewer number of registers that are kept separately in the Republic of Srpska, Federation of B\&H and the District of Brcko and as follows: Cadastral Books; Land Register; Register of Births, Marriages and Deaths; 
Records of Residence; Citizens Records; Records of Displaced Persons; Register of Civil Servants; Register of Economic Entities; Register of Taxpayers; Budget Classifications; Capital Projects; Tax Records; Register of Regulations; Programs of Statistical Surveys; Statistical Standards etc. Which registers and where they are kept can be seen from "Analysis of the Existing Partial Registers in B\&H" [10].

If we look at the separate registers as service users then we can not understand why this is so. If we look at these registers from some other aspects, then we can have a different opinion.

How to connect individual registers and in what form? Is the solution computer science in a cloud? How much cost savings in serving could public administration accomplish if partial registers were in an appropriate manner available to everyone? How to connect these registers with ontologies and knowledge bases? How much cost savings could service users achieve?

Now the service user in the administrations, administrative organizations and local self-government units (municipalities/cities) gives the same data for several times and everything is repeated in every contact with the public administration (Figure 1). To prevent this of happening the public administration of these areas must link the separate registers. The user should be given access to the personalized services which are simple, safe and flexible. Seeking and receiving services should be provided to all communication channels, and access through single access points. From user should only be downloaded those data and information necessary for delivering the service and the same data should only be taken once from the user. In all this we should always think about the privacy of the user and services. The service should be ensured to all citizens including the persons with disabilities and older persons, in accordance with specifications for electronic and mobile services (e-m-Services) [11].

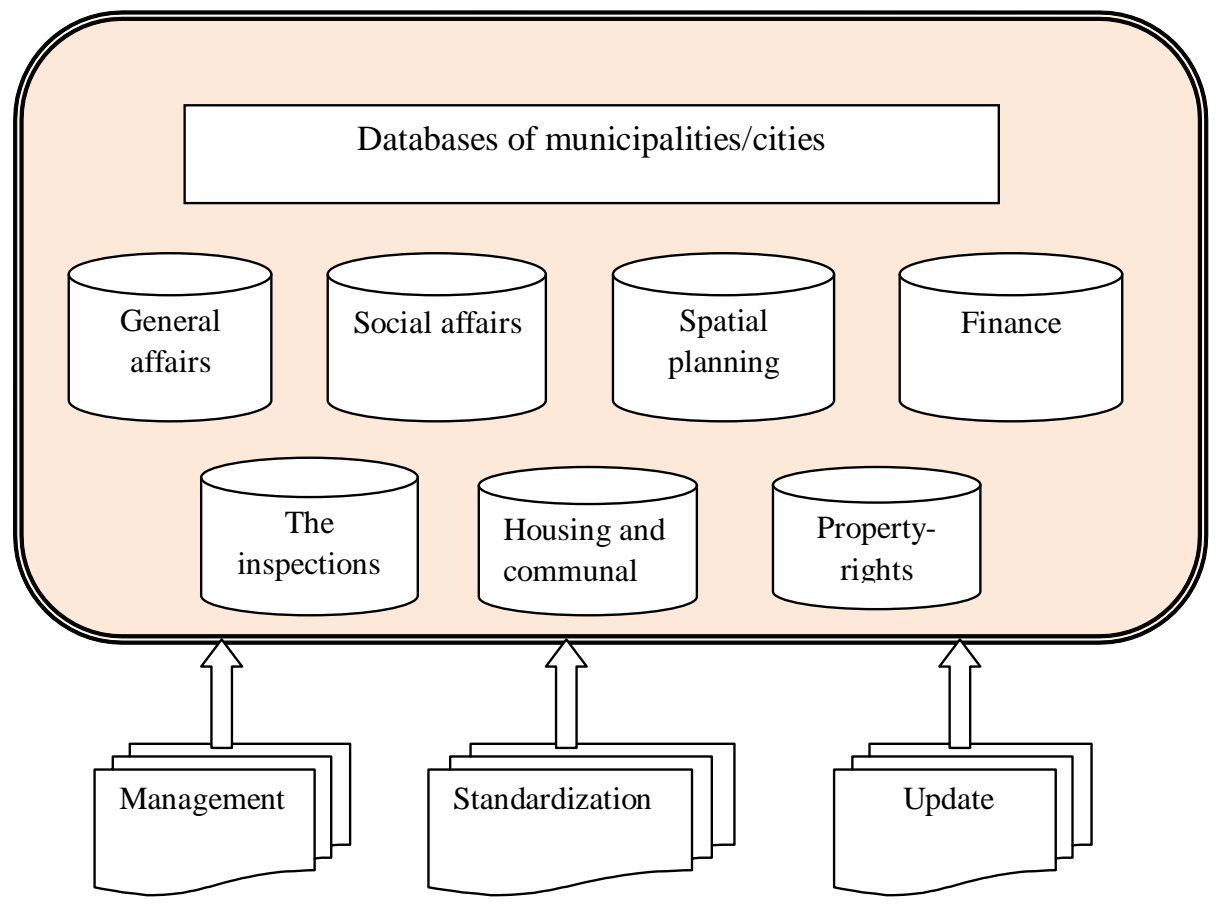

Figure 1. Isolated islands of data

Databases that run local self-governement units are different from each other. There is no standard by which it would be run and archived data in the unique format and form. It is not invested enough effort to reach their standardization (Figure 1). The goal about unique standard and unique databases of local self-government units of Bosnia and Herzegovina is now just a goal on which anyone hardly does anything. Due to various existing databases among local self-government units, the process of extraction of factual knowledge today is necessarily implemented specifically from one local self-government unit to another.

All the data about the economic and service entities and bank payments are kept in the local databases. In order to build an automated service information system it must be provided access to these data in the time of need.

In a certain local self-government units databases by structure and organization vary considerably from each other. It has not yet been adopted the standard by which the data in municipalities/cities would be uniquely housed in a uniform structure. In this region $(\mathrm{B} \& \mathrm{H})$ little is being done on that.

Due to different existing databases in the local self-government units, the process of extracting the appropriate knowledge must now be implemented separately from one municipality to another.

If we know the situation in our country and in the region and what is planned in the European Union we can think about necessary steps for the implementation of more efficient electronic, mobile and intelligent business in the public 
administration (e-m-i-Government). The first step is to work on the infrastructural linking, implementation of interoperability and the implementation of ontologies.

\section{ACCES POINT}

In the access (reception) point it is ensured the reception of requests for the service of the user (primarily in digital form). The use of software agents provides a creation of service, correspondence with the user and archiving of cases with the use of modern information and communication technologies.

Speaking very roughly service process consists of the submission of the request, reception, processing (creating solutions) to dispatch and back up solution. It is interesting to see in which process are needed digital skills and for which service processes should be created ontologies. In the service system of the public administration this is certainly processing (creating solutions) and there are necessary databases and knowledge. Other processes are already informatically well covered (which does not mean they can not be improved).

We would like to have (and in this paper we suggest) a unique access point (centralized portal) of the public administration with the service users. Access to services should be provided via computer, mobile device, phone, digital TV, fax and so on. This access point will be built around ontology, and is shown in: Figure 2 "The new service solutions."

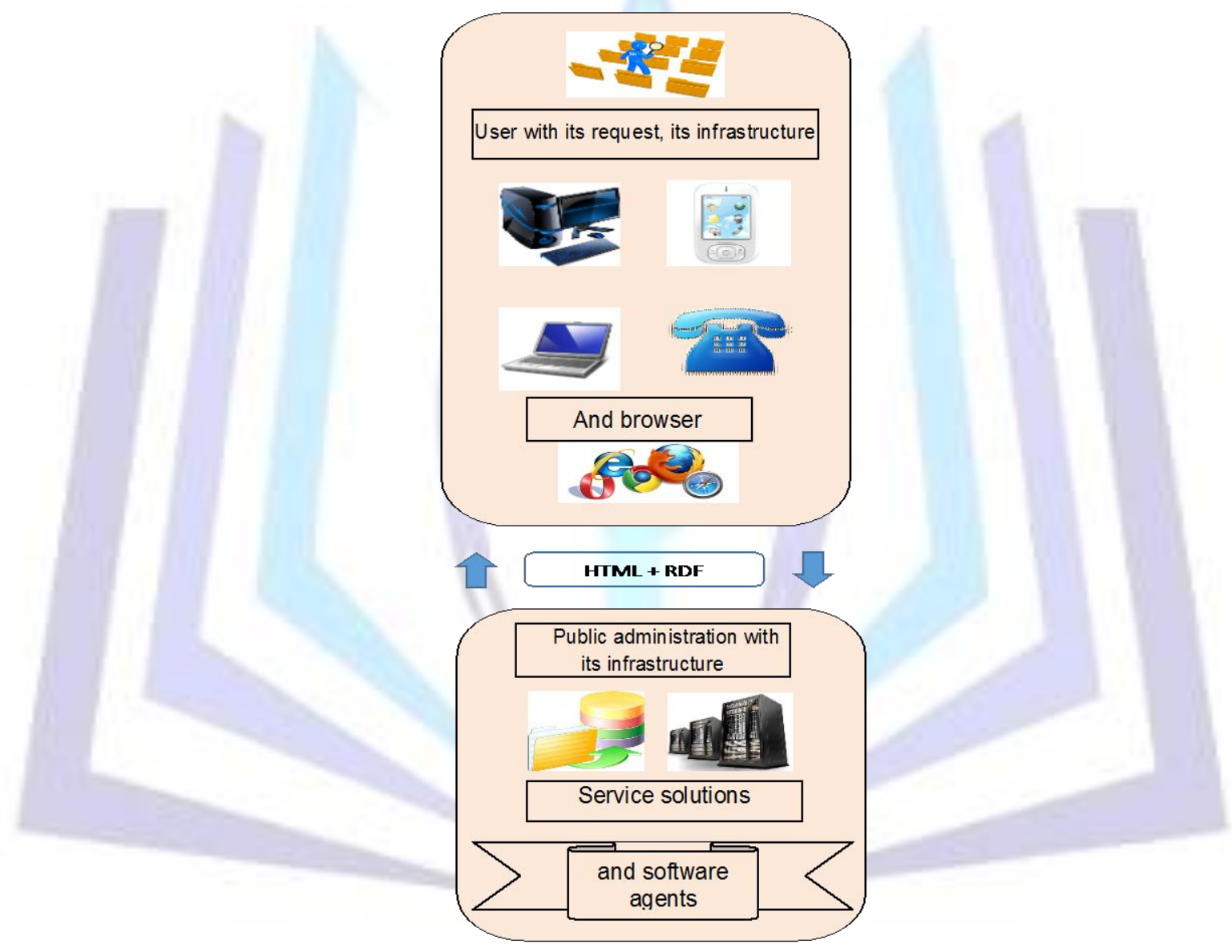

Figure 2. New service solutions

\section{ONTOLOGY}

The notion of ontology is very wide and represents more a conceptual idea than some strictly defined formalism for expressing knowledge. In other words, there are a number of different formalisms which represent knowledge in a manner which is included in the concept of ontology. It is crucial that in the formalism itself there is a possibility of structuring the observed domain with the definition of the concepts in the domain and the relations between them.

Ontology describes a certain area through a given terminology (vocabulary areas), basic concepts, the classification of these concepts and the connection between the concepts with defining the rules that govern between them. It is a detailed description of some area of knowledge with formal definitions of relationships and connections among the various elements of that area [12]. Ontologies are used for the representation of knowledge, management and organization of knowledge, modeling and shaping the databases, search and retrievement of the desired knowledge.

Some other definitions of the ontology are: 
"Ontology is an explicit specification of conceptualization. "[13]

"Ontology is a formal, explicit specification of shared conceptualization." [14].

"Ontology is a formal specification of common conceptualization" [15]. Each of these concepts is hiding properties and characteristics of ontology. Ontology can be also defined as a set of terms and relations among them, which describes a specific domain or area of knowledge. The domain can be any area of a subject, regardless of its level of generality.

Conceptualization - is an abstract model of the world shown by using concepts and their connections. By using it, it attempts to structure the generality of terms with their definition, connection and rules and constraints on behaviour.

Specification - connects elements such as components of ontology that are used for modeling of knowledge, patterns of knowledge representation used to display components, and the language used in the implementation of ontology within the specified patterns of knowledge representation.

A formally written ontology - a precondition which can be used (understandable to the computer) by the system. Ontology is not active and can not be run like a program, but it declaratively shows a certain knowledge that is being used by a program.

Common agreement on the structure and purpose of the ontology - is installed as shared, common knowledge of the group. Thus, ontology is developing in dynamics by which progresses exchange and adoption of knowledge about, for example, more efficient and more effective serving in local self-government units. This opens up opportunities for sharing knowledge and its reuse and semantic interoperability among agents and programes.

In computer and information sciences ontology is a data model that represents concepts within a domain and the relationships between those concepts. It describes concepts and relationships that can exist for an agent or community of agents and represents a set of definitions of formal dictionary. Ontology defines the terms that are used to describe and present some of the areas of knowledge, that is, it presents a formal, explicit description of terms used in the domain that the ontology desribes.

Paulheim [16] defines three reasons for the use of ontology in the business systems: better layout, better interaction between the system and the user, a unique knowledge base. The same reason for the use of ontologies applies for its implementation in the public administration.

\section{1. The process of designing ontologies}

Creating an ontology is an iterative and constantly upgradeable process. In order to accurately determine the area that covers ontology, it should be given answers to the next questions: Which domain in the public administration of Bosnia and Hercegovina is described by ontology? In what kind of purposes will ontology be developed? What kind of questions should ontology be able to answer? Who will be the beneficiaries of an ontology? Who will be responsible for maintaining the ontology?

In the process of designing, the answers to these questions can change. A good way to determine the areas that the ontology covers is the preparation of specific questions that a knowledge base and inference mechanisms can respond. Before you start designing the ontology it is necessary to examine the existing ontologies. If they exist, it is necessary to update the defined concepts and connections and always bear in mind that it is an iterative process. An important characteristic of ontologies is that it can be updated or it can be added new terms and connections, and is the subject to revision and correction.

Which method is going to be used depends on the designer of ontology, as well as the character of the ontology. The most commonly used is the combination method - it starts from the concepts that are of the utmost importance. Only then the hierarchy among classes is determined. Then the properties of classes are defined.

When introducing new concepts in ontology it can occur a problem whether they will be represented as a class or a feature of that class. If these concepts are without properties, in the purpose of good layout it is more useful to define them as classes. The ontology should be maintained and updated in view of the acquisition of new findings from the field of public administration. To avoid possible errors, and for the model to be more credible, it is necessary to define the following rules in determining the names of concepts, which will adhere to the designer: [17]

- $\quad$ is it permissible to use the same names for classes, properties of classes and instances;

- does the system differ small and capital letters;

- do the names of the classes have singular and plural;

- whether they will use prefixes and suffixes so the names of the classes and their properties would differ;

- whether to use abbreviations for the names or not etc.

It is important to know if we are talking about ontology to which it relates, that is, the context in which it is used. Here we are primarily going to deal with opportunities of sharing knowledge in local self-government units and its reuse. We use it as a set of definitions of formal vocabulary of the public administration, as a building block of the semantic web, and it contains usable parts of the knowledge of e-m-Service.

The adaptation of the existing information system of local self-government units can be carried over the ontologies because they specify the knowledge that the new information system must include in order to perform the assigned tasks. In order to effectively enforce the shaping of such a system it is necessary to have knowledge of the service 
system of municipalities/cities (local self-government units). System of serving is very complex, and besides that also specific in the environment in which it works. It is therefore necessary to make a model of the entire system, which can then be used for construction or re-engineering of the computer programs.

The model must be such as to provide several ways for finding needed services and flexible enough to allow the addition of new terms in the future.

Ontologies specify the knowledge which the IS of the public administration must embrace in order to make the appropriate serving. So we could be able to quality shape this complex system we must have adequate knowledge about the area. Systems of serving in the public administration are complex and also specific in the environment in which they operate. It is necessary to build a model of the system of the public administration that will represent its reduced and simplified picture (Figure 3). For the observed area of serving in this region there is no ontology, so first of all it is necessary to make one. We will develop a new model of work and serving in the public administration on the new ontology which describes system of public administration in the territory of Bosnia and Herzegovina.

If you look at the current methods of integration of ontologies it can be seen that the methodology suggested in this paper is different from all the previous ones. An important difference that here we emphasize is the possibility of providing greater satisfaction of the user with the services and more efficient and effective serving.

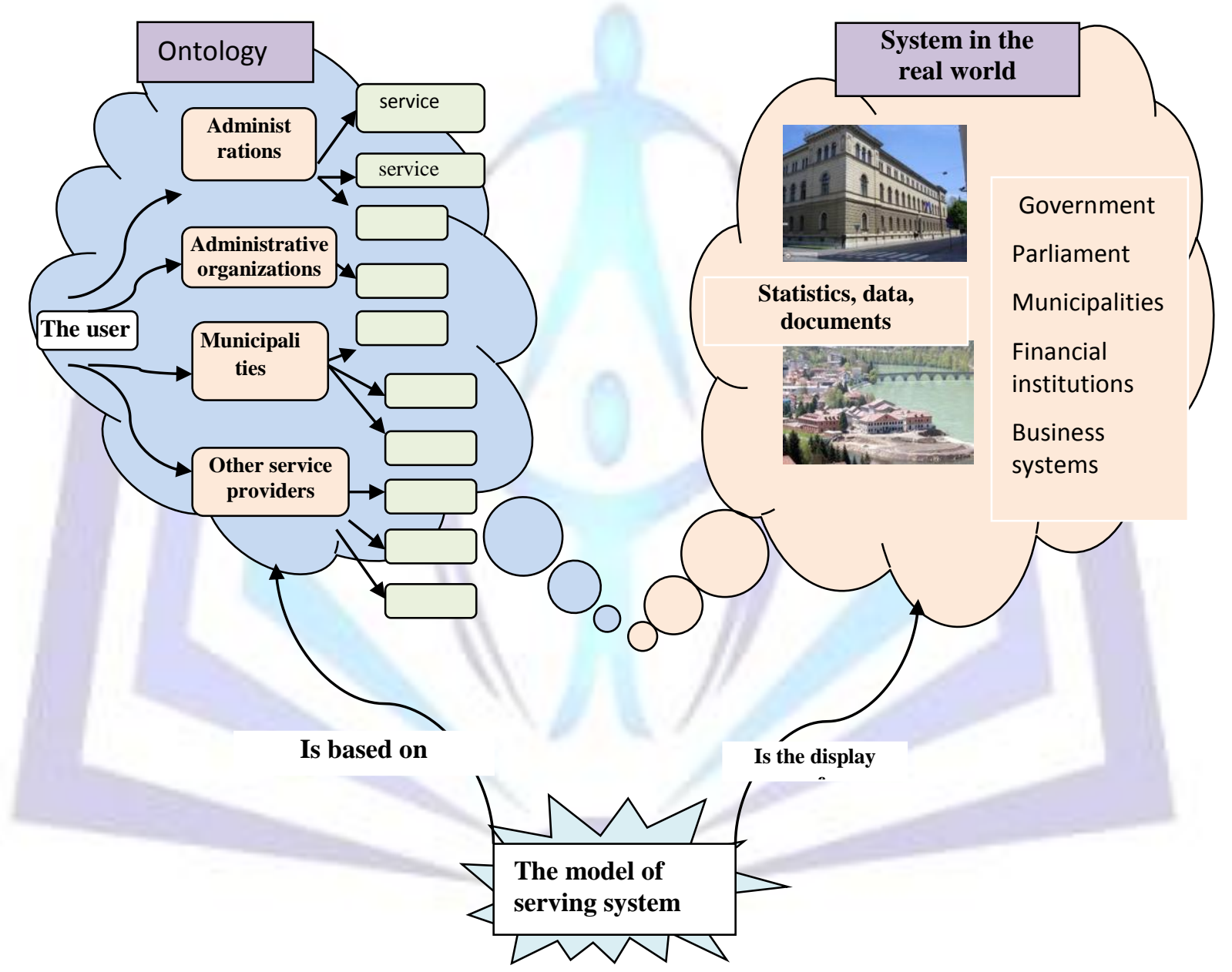

Figure 3. Service model

The use of ontology will provide us the way to complete the knowledge of the specific area of serving of the public administration.

The actual contribution of the ontology should be viewed in the internet environment where interaction between the users of services and the public administration over the web should reach the level at which the web information space is sufficiently readable for computers. It should provide the user an accurate reprezentation of what he seeks. We should use the semantic web which is an extension of the current web. This information is given on a well-defined way (using ontologies) which then allows better cooperation between computers and its users.

In this paper I want to propose the necessary knowledge for providing services of the public administration to its users. Due to the limitations of the paper we will extract just a small part of the necessary knowledge naming them just for the purpose of understanding a new service concept of giving services of the public administration in Bosnia and Herzegovina. 
Participants (attendees) in the service process are: the service users (legal entities and individuals), and service providers, administrative bodies (administrations, administrative organizations), local self-government units (Figure 4). Those participants that are more important in our observation are highlighted by a certain background color.

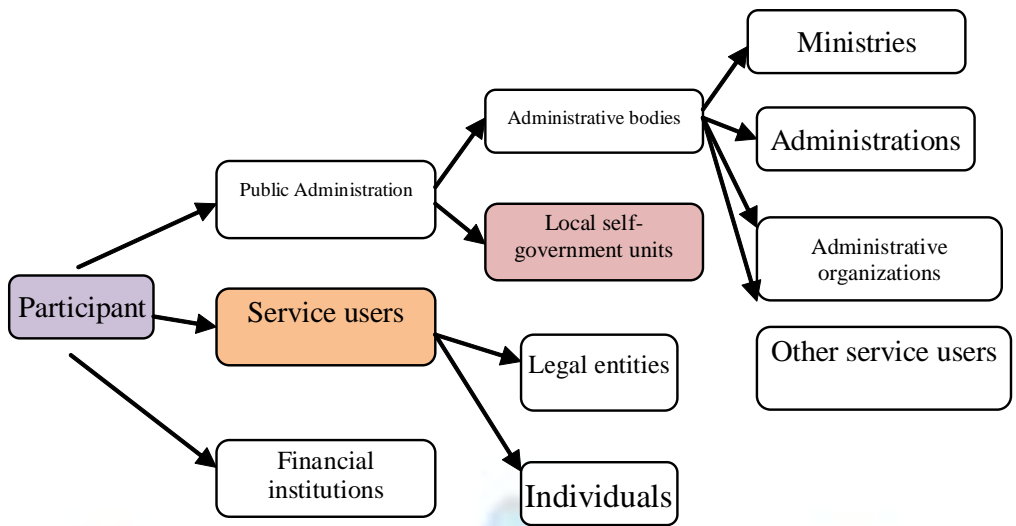

Figure 4. Participants in the ontological service process

Here we consider the problem of a user (business or service entity) whom is needed a DECISION on extended working hours of a certain day and certain number of hours.(For example, florists or catering facility). Such a decision in these areas is issued by the local self-government units (municipalities/cities). We want to use all the possibilities that are given by the mobile and computer systems. Consider the steps (procedures) that are necessary to implement. Due to the limitness of the paper we just roughly mention some procedures and we do not go into their technical realization.

1. The user creates and sends a message by a mobile phone about the necessity of work of a certain day (eg $8^{\text {th }}$ March) longer than the prescribed working hours. In the message it must be contained identification number of a business entity that submits the request and asks for the extension of working hours.

2. Reception of the message on a certain computer in the local self-government unit (municipality/city).

3. Opening of a message from a software agent or a system administrator.

4. Activiting the software that should run the appropriate application for solving the requirements of the users.

- Loading the appropriate form,

- $\quad$ Auto-fill data - activation of database about the licenses to work for all subjects,

- $\quad$ Filling the form with necessary data from the database and received messages.

(From the message the system should recognize the identification number and check whether there is such a bussines entity and whether the message is received from a mobile device that is in the database of registered users)

5. Appropriate software (agent) submits filled approval of extended opening hours on e-Signature.

6. Signed authorization in e-Form is archived and is send to an applicant a part of the decision about the approval to work longer on the required day (or rejection of the request on working hours).

7. The corresponding software of the appropriate place (field) on the approval of extended work copies data in the message that will be forwarded to the applicant. The message is sent to him on the mobile device (phone).

8. The decision to grant a prolonged work in e-Form the softwer agent forwards: to communal inspection, inspection of work and all those who need it.

Is this solution just a list of good wishes or fullfilment of a dream about a complete connectivity of electronic, mobile and intelligent business, about a complete connectivity of e-m-i-Government and e-m-Service? What knowledge and what procedures are necessary to a computer system to do the whole application alone and to deliver the user an appropriate solution?

For this complex and challenging concept could work out in practice in this area, it should be dealth with a lot of details in each of the above steps. There are still a lot of details that are not mentioned here (not even in an idea), and without which the unique concept of e-m-i-Government can not fully become operational.

It must be explained and given elements that exist in this world and their interconnections [18]. This will help computer workers (and all others) to learn faster and better the settings of so distance unfamiliar world. At the begining the employees will be able to perceive a common area of interest and not just their tasks and problems. Making of the ontological model will be a good basis for the development of different information system of service bodies and the 
implementation of the ontology would enrich the opportunities of making and using more knowledge in the new software solutions.

Ontology that we can achieve on such grounds enables the control of the administrative acts which is foreseen by legislation and the communication between the administrative units that are involved in the service process. That can be a good basis for the implementation of e-m-Service.

The ontological model that we propose is based a lot on the researchs of Savvas [19] i Vassilakis [20] who were the first to present a method of modeling of the ontology in the domain of e-Administration.

Ontological model of the public administration must give the structural aspect of the public administration and a complete description of documents that appear as a product of public administration (service provider).

Textual aspect must be presented in the ontology through administrative documents: official gazettes, documents produced in the course of communication between service user and the public administration, and prescripts and decisions relating to administrative procedures.

In determing the ontological model of the public administration it should be analyzed the following domains: participants, documents, service processes and digital services.

The implemented model like this should provide a fully automated service.

In this paper we will only briefly mention the documents mostly because they have only been in the written form until now and now are increasingly using digital. Here, for us the necessary strategic documents are "Official gazettes" and the various administrative instructions and templates (Figure 5.).

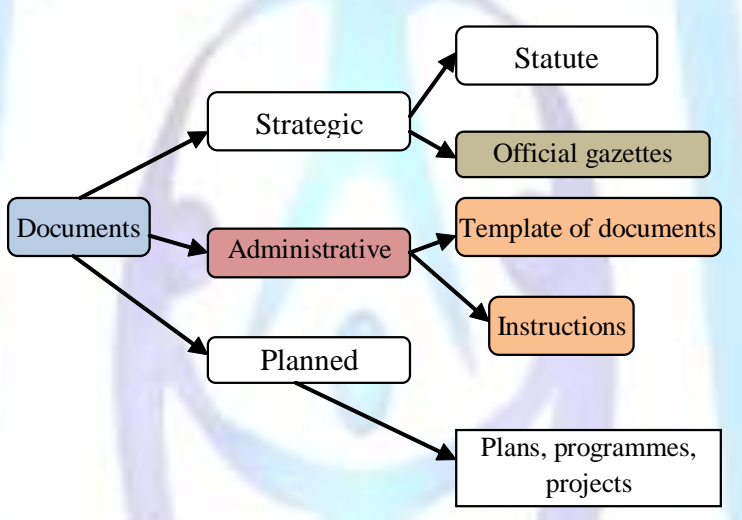

Figure 5. Documents

For us the most important output documents are the one that arise as the result of work of the public administration in providing services. In order to get the appropriate output document the service user must submitt a proper submission. According to section 52 under " the submissions are included requests, forms that are used for the automatic data processing, suggestions, applications, petitions, appeals, objections and other communiques with which the parties are refering to the authorities. Submissions are, as a rule submitted directly or sent by mail in writing or verbally communicated for the record, and it can be declared by telegraph, or by fax. Short and emergency announcements can be made by telephone if this is possible by the nature of things" [21]. In this paper we are interested in and we will observe only the submission and the output document in a digital form.

First of all the operating procedures should be well analyzed - classes, properties, relationships, concepts. Now we must introduce an automated procedure based on digital technologies, primarily in seeking and receiving services (Figure 6.).

It is necessary to define the internal and external services. Internal services are those that should provide only the creation of the output document and the external services should provide communication with the client, the bank through which are received the payments for the executed service and the like.

When creating the output document the appropriate software agents load the created template of the output document and from the database and the base of knowledge are taking the missing data. The input data consists of a series of variables that we use to fill in the missing data in the proper output document. Here, under the base of knowledge we mean the knowledge presented in the form of unstructured set of facts and rules and it has a role to help all the users to find the knowledge they need and to share it with other users.

IT and legal experts are responsible for creating an appropriate templates of the output document and the corresponding e-Service based on the semantic web and ontologies. 


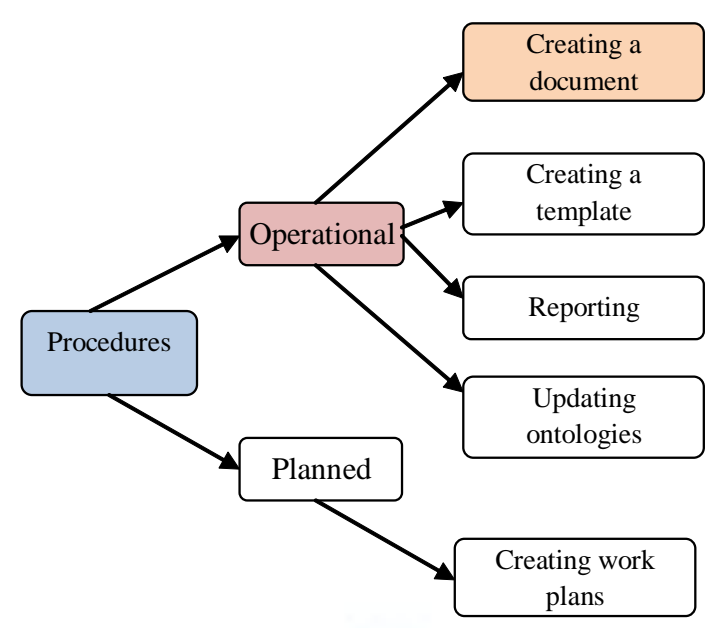

Figure 6. Procedures

\section{2. Necessary knowledge about the facts of serving}

The output documents that need to be enacted in the service process in the local self-government units are enacted based on the individual requests of individual service users. In the introduction we have looked at the problem of getting the "permission" for the extended work of the economic or the service entity for the certain day and a certain number of hours. Among other things, to afford a proper solution software agents prior to everything must have available knowledge for the creation of output document, data about the registered subject that files the request, whether it has fulfilled the obligations towards the society and whether it meets all the legal requirements for obtaining the positive solution.

The structure of ontology of the knowledge base is solid and defined in advance. In our observation, ontology defines knowledge of the public administration on the basis of which conclusions are made using a system of self-service and personalization. The process of inclusion of factual knowledge in the public administration of B\&H must be implemented from the start because there is no respective knowledge in digital form. We need a high quality knowledge base for all local self-government units (later the whole public administration). The environment in which can be seen the implementation of factual knowledge in local self-government is shown in Figure 7.

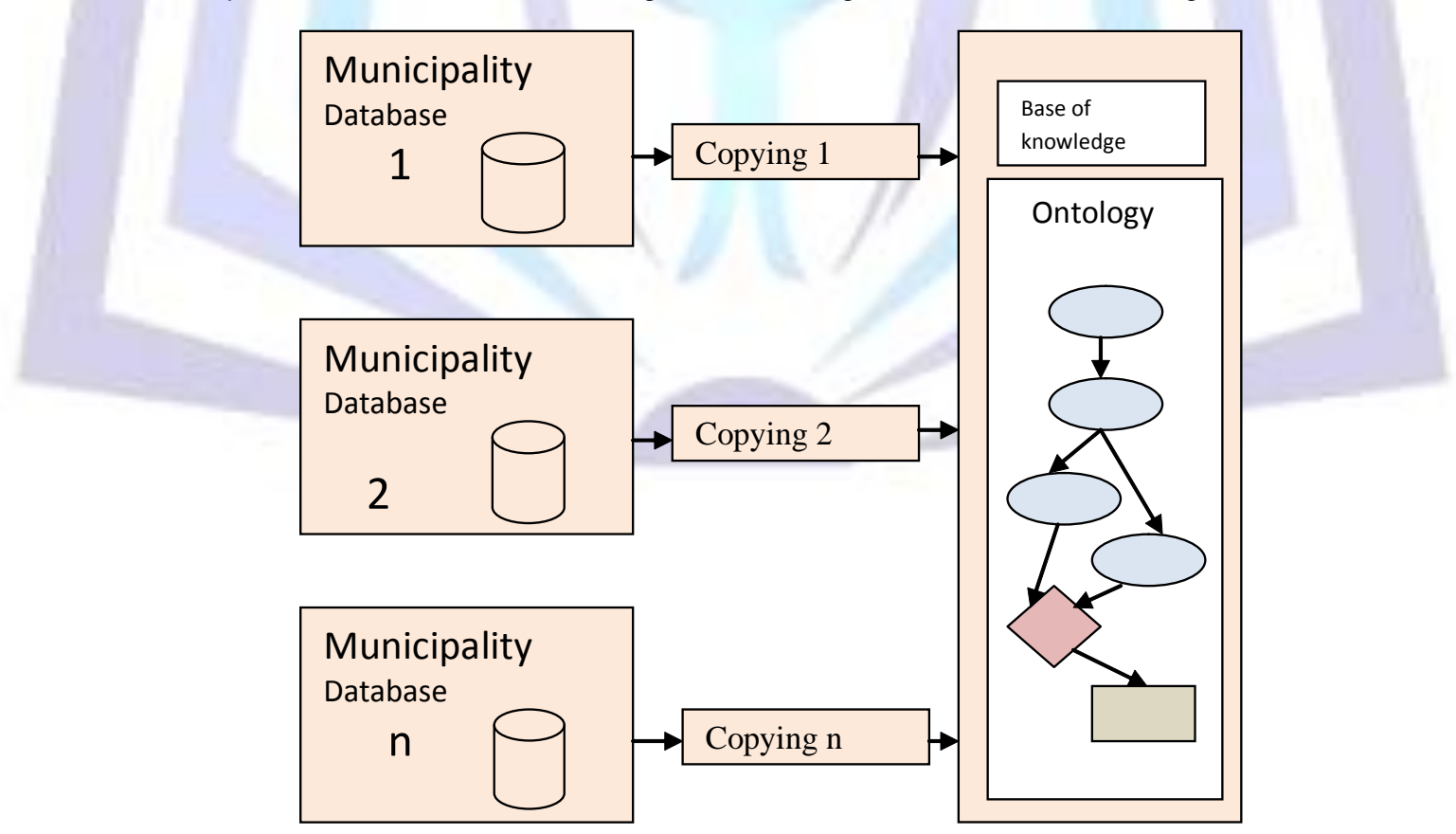

Figure 7. Knowledge base of the local self-government

If the local self-government wants to implement the concept of self-service and personalization based on ontologies it must implement specific copying from its internal data bases towards ontology in the knowledge base. 
Solution that can provide a more quality knowledge of the local self-government units in one location is presented in the Figure 7. Copying of information and knowledge that are contained in the individual local self-government units (municipalities/cities) can provide us with the necessary ontologies.

The problem of copying the data from the relational base to ontology appears in the domain of the semantic web where there is the need for including data stored in the relational bases in an active and dynamic pages of the semantic web.

In order for the service information system could be taken into an account all the current features of a certain economic or a service entity are recorded in the relational databases, it is necessary to enable the transformation of data from the relational base in an ontological structure. Thus the factual knowledge could be included in an automated process of serving. To make this possible it is necessary to define the formalism that the data obtained by $S Q L$ queries puts in the appropriate locations in ontology.

\section{PRODUCTION RULES AND THE KNOWLEDGE BASE}

Knowledge base in our automated service information system serves for gathering, recording, organization and browsing of knowledge and it should optimize each of the steps.

Positive resolution of requests for the extension of working hours an applicant may receive if they fulfill certain conditions. First of all the obligations must be settled according to the "Tax administration", paid taxes, properly completed application ...

The competent body of the local self-government unit (municipality/city) defines working hours of the economic or service entity and issues a decision on the extension of working hours. In doing so the competent authority must ensure that their work does not disturb the public order. The competent authority conducts its activities in accordance with the Law on Local Self-Government (Official Gazette of the Republic of Srpska num. 101/04, 42/05, and 113/05) Law on catering (Official Gazette of the Republic of Srpska num. 15/10) and the Regulations or Decisions of the Local Self-government units on the working hours of the economic and the service entity. Each local self-government unit has resolved it differently and with its acts, by content and terminology.

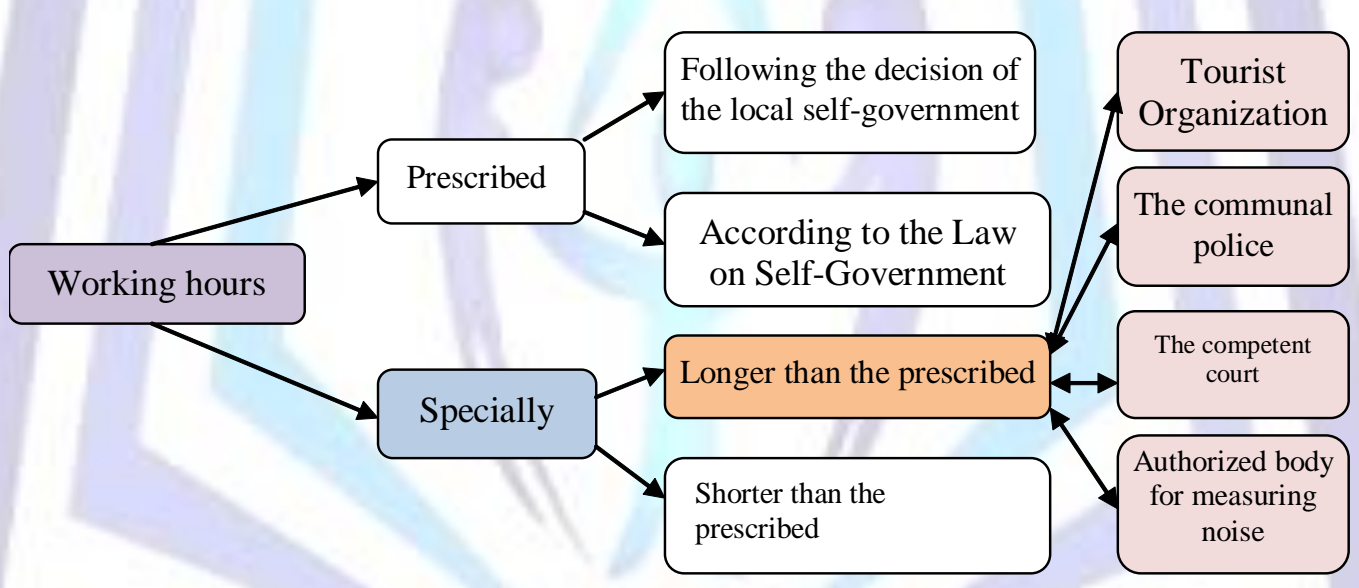

Figure 8. Working hours

Criteria for approval of extended working hours.

- $\quad$ The finding and the opinion of the competent body for noise measurement

- Recommendation of the tourist organization that the object is important for the tourist industry.

- Evidence of no criminal record for disturbing public peace and order (competent court) or exceeding the working hours (Figure 8.)

IF “misljenje_organa_pozitivno" AND "preporuka_turisticke_organizacije” AND "nije_kaznjavan" AND "nema_prekoracenje_radnog_vremena" THEN = "Prihvati zahtjev - izdati_rjesenje"

If you have completed the appropriate prerequisites and entered an appropriate knowledge into the knowledge base using ontologies and production rules we can think about automated service. Production rules say what you should do if you meet certain condition, ie a certain situation exists. Standard construction is : IF "event" THEN "consequence".

Knowledge base: Production rules are based on the oldest form of the predicate logic form "IF ... $\rightarrow$ THEN". Each production rule includes a requirement that must be met before you perform an action.

The general form of the production rules has the following form:

IF situation $s$ THEN action a

IF condition c THEN consequence c 


\section{IF $p$ THEN s TO DEGREE $d$}

In our example of the search of the extension of work we can appoint some concepts in the domain and form relations between them while using appropriate rules in the form:

IF "tax paid" AND "request is complete" AND "space outside residential buildings THEN = "issue a prescript" IF "tax paid" AND "request incomplete" AND "the space outside residential buildings" AND "residents complain about the noise" THEN = "reject prescript"

IF "tax paid" AND "request incomplete" AND "the space outside residential buildings THEN = "reject prescript"

IF "tax paid" AND "request complete" AND "residents complain about the noise" THEN = "reject the request"

We now have a large number of languages and tools for describing ontologies. Among ontological languages mostly is in the use OWL (Web Ontology Language) and ontology editing tool „Protégé-OWL“.

The application that was made to store knowledge in this project pilot was carried out in the Visual Studio.NET programming environment using $\mathrm{C \#}$ (C Sharp) programming language. The appropriate database is done in Microsoft Access and the merging and work with the database is done by ADO.NET technology and OleDb connection with the database.

\section{CONCLUSION}

The new concept of the e-m-i-Government and e-m-Service based on the semantic web and ontologies represents the main challenges in redefining the role that gives the public administration.

Different modeling of the service system of the public administration, creating and using ontology and management of administrative processes will accelerate a complete automation of the service system of the public administration.

In this paper we proposed an ontological model of an automated service information system of the local selfgovernment units (municipalities/cities). The proposed model enables the automatic creation of the output documents that arises as a result of work of the public administration.

The focus of the work was related to the participants, documents, business processes and service logic and the automation of services based on the semantic web and ontologies.

The proposed methodology and for now far less implemented pilot solutions have yet to demonstrate their practical utility in the public administration of Bosnia and Herzegovina. For full implementation it will take a little longer period of time so we can say that this is a long term goal. The application of the proposed methodology in some other areas has yet to show adequate results. This area will be very interesting in future studies.

\section{REFERENCES}

[1] Radivojević M., Concept for Advanced Electronic, Mobile and Intelligent Government Services, International Journal of Managerial Studies and Research (IJMSR) Volume - 1, Issue-3, H.No: 8-3-229/A/7, 2013.

[2] Radivojević M., The implementation of new technology solutions and their impact on user satisfaction in public administration, "International Review of Social Sciences and Humanities (IRSSH)", ISSN 2248-9010 (online), ISSN 2250-0715 (print).

[3] Article 65 Law of the Republic Administration ("Official Gazette of the Republic of Srpska” No. 118/08)

[4] Jones, G.R. Organizational theory, design, and change, fourth etition, New Jersey, Person Edukation Internetional, 2004.

[5] GENERAL ADMINISTRATIVE PROCEDURE ACT ("Official Gazette of the Republic of Srpska", num. 13/2002, 87/2007 and 50/2010)

[6] http://sr.wikipedia.org/

[7] Radivojević, M., "The Impact of the New Technological Solutions to the Satisfaction of the Users in the Public Administration", International conference, Infotech 2013, Aranđelovac, Republic of Serbia, 2013

[8] Hodge, B. J., Anthony, W. P., Galas, L. M., Organization Theory: A Strateggic Approach, New Jersey, Pearson Educatin, 2003.

[9] Agency for the Identification Documents, Registers and Data Exchange

[10] REPORT ON THE ANALYSIS OF THE EXISTING PARTIAL ELECTRONIC REGISTER, PROJECT: Design and Establishment of the Frames of Interoperability and Standards for Data Exchange, page 72., Sarajevo 2013.

[11] Radivojević M., Concept for Advanced Electronic, Mobile and Intelligent Government Services, International Journal of Managerial Studies and Research (IJMSR) Volume - 1, Issue-3, H.No: 8-3-229/A/7, INDIA, 2013.

[12] Klarin K., "Ontology and the Development of the Information System in the Public Administration, "CASE 23, Zagreb, 2011. 
[13] Gruber T. R., "A Translation Approach to Portable Ontology Specifications," Knowledge Acquisition 5(2), page 199-220,1993.

[14] Borst W. N., "Construction of Engineering Ontologies for Knowledge Sharing and Reuse," Centre for Telematica and Information Technology, University of Twenty, Enschede, The Netherlands, 1997.

[15] Borst W. N., "Construction of Engineering Ontologies for Knowledge Sharing and Reuse," Centre for Telematica and Information Technology, University of Twenty, Enschede, The Netherlands, 1997.

[16] Paulheim H., , F., Probst, Improving UI Integration with Formal Semantics. SAP Research CEC Darmstadt Bleichstrasse 864283 Darmstadt, Germany.

[17] Aida Slavić: The Semantic Web, Systems for Organization of Knowledge and Network Standards (http://dzs.ffzg.hr/text/Slavic_2004.pdf (16.3.2012.))

[18] Mika P., Akkermans H., "Analysis of the State-of-the-Art in Ontology-based Knowledge Management," EUIST Project IST-2001-34103 SWAP, Vrije Universiteit, Amsterdam, 2003.

[19] Savvas I., Basiliades N., , A Process- Oriented Ontology-Based Knowledge Management System for Facilitating Operational procedures in Public Administration. // Expert Systems with Applications: An International Journal. 36, 3(2009), pp. 4467-4478

[20] Vassilakis C., Lepouras G., Ontology for e-Government Public Services. // Encyclopedia of e-Commerce, eGovernment, and Mobile Commerce, 2006, pp. 721-728.

[21] GENERAL ADMINISTRATIVE PROCEDURE ACT ("Official Gazette of the Republic of Srpska", num. 13/2002, 87/2007 and 50/2010)

\section{Authors biography:}

\section{Radivojevic Mladen, Ph.D}

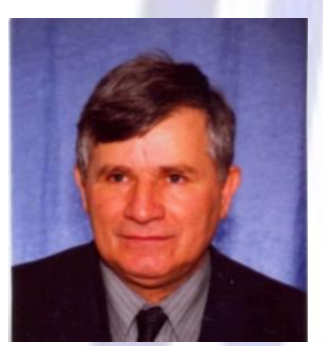

I was born on May 14, 1952, in Gradiska, Bosnia and Herzegovina.

Since 2000 I work with the Ministry of Administration and Local Governance and as the professor for informational group of subjects at the Faculty for business studies, Banja Luka Collage, Law Faculty in Banja Luka and at the Faculty of Economy at Sarajevo University.

Doctoral theses titled „Methodology for implementation of e-Government concept in $\mathrm{BiH}$ public administration reform" were successfully finished in 2005 at the Faculty of Informational Technologies in Mostar and I gained scientific degree as „Doctor of informational science“.

I published 27 books and 155 papers in various scientific and public publications.

\section{Kristijan Ristic, Ph.D}

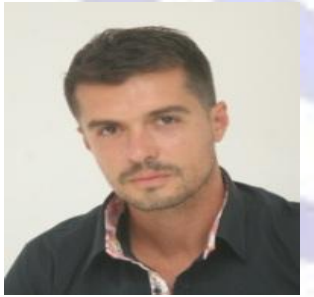

I was born on January $7^{\text {th }} 1976$ in Belgrade. I completed basic studies at the Faculty of Economics in 2002 in Belgrade,where I attended master studies in Fiscal and monetary management and management of social affairs department. Master's thesis under a title "Budgetary policy and economic stability" I defended on BK University,Faculty of Management, and thus gained scientific name Master of Science in Economics. PhD thesis under a title "Monetary and fiscal policies of the European Union in situation of global economic crisis " I defended on 05.05.2011. on Faculty of Trade and Banking of Alpha University of Belgrade and thus earned the title of Doctor of Science in Economics.

Slađana Lolić, Ph.D

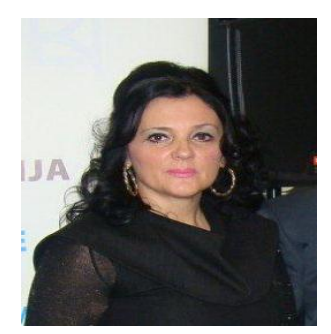

Slađana Lolić was born on 18th September 1969 in Ključ,Bosnia and Herzegovina.She'd got master's degree in 2009 and doctor's thesis "Menagement of knowledge and menagement of human potential" vindicated in 2012 at The University of Business Studies in Banja Luka,where she works as assistant professor of these subjects:Event Menagement,Business culture and ethics,Menagement of controling human resources,Menagement of human potential and Menagement and marketing of service sectore.She has published two books and eleven professional articles.She has been the leader of many projects,such as:CIVITAS,Education for Democracy,Denmark organization,Inclusion,Eco-project,CRS,Educa Aid,EFP-Education for Peace (coordinator),Step by Step,ECDL-European Computer Driving Licence and Official Certification English Language Course.She has been taking a part in many professional Symposiums and Conferences in Prague,Neum,Tuzla,Sarajevo,Banja Luka and Belgrade.She has twenty-two years teaching experience. She has been married and she is a mother of one child. 